\title{
An Examination of the Influence of Organizational Structure Types and Management Levels on Knowledge Management Practices in Organizations
}

\author{
Jen S. Steiger ${ }^{1}$, Khalid Ait Hammou ${ }^{1} \&$ Md Hasan Galib ${ }^{1}$ \\ ${ }^{1}$ Alliant School of Management, Alliant International University, San Diego, CA, USA \\ Correspondence: Jen S. Steiger, Alliant School of Management, Alliant International University, San Diego, CA, \\ USA. E-mail: jensteiger@yahoo.com
}

Received: March 11, 2014

Accepted: April 4, $2014 \quad$ Online Published: May 22, 2014

doi:10.5539/ijbm.v9n6p43

URL: http://dx.doi.org/10.5539/ijbm.v9n6p43

\begin{abstract}
The purpose of this study was to investigate the difference between organizational structure types, and management levels, in terms of perceived levels of knowledge management practices within organizations. Data were collected from a sample of 155 individuals employed in San Diego County by way of a web-based survey, and were analyzed using analysis of variance (ANOVA). The results of the study indicate that the knowledge management practices of knowledge transfer, information filtering, and knowledge culture are influenced by organizational structure type. According to the study, knowledge sharing training is not significantly influenced by organizational structure type. Furthermore, the results of the study indicate there is no significant influence of management level on the knowledge management practices of knowledge transfer, information filtering, knowledge-sharing training, and knowledge culture. In summary, the results of this study solidify the assertion that organizational structure types do influence knowledge management practices.
\end{abstract}

Keywords: knowledge management, knowledge transfer, information filtering, organizational structure

\section{Introduction}

Organizations generally accept that strategic assets include such elements as operational efficiency, market development and sales. An organization's structure is closely tied to its strategy, and the two are deeply intertwined. A less commonly accepted strategic asset is knowledge management, and thus the influence of organizational structure on knowledge management is still largely unknown. However, knowledge management is an increasingly relevant element of organizational success(S. C. Chong, Salleh, Noh, Ahmad, \& Sharifuddin, 2011; Garcia Del Junco, De Reyna Zaballa, \& Garcia Alvarez de Perea, 2010; Lerro \& Schiuma, 2009), and it should therefore be considered a strategic asset. In particular, efforts should be made to understand four key components of knowledge management-knowledge transfer, information filtering, knowledge-sharing training, and knowledge culture-and the influence of organizational structure upon them.

Unlike other assets, such as sales, knowledge is ambiguous by nature, and difficult to quantify and measure (Tsoukas, 1996). This ambiguity can hinder the acceptance of knowledge as a strategic asset. Organizations face a significant challenge in defining and capturing the knowledge held by individuals and within the organization (Hari, Egbu, \& Kumar, 2005). Without effectively quantifying knowledge, it is impossible to measure it, and this poses important challenges to strategic management.

An additional challenge is developing an understanding of how knowledge transitions among individuals and throughout other organizational entities. Conscious and subconscious filtering occurs any time information or knowledge is exchanged (Smoliar, 2003). Filters affect when information is shared, what kind of information is provided, and how the information is interpreted (Brownell, 1991; Christensen, 2002). Much meaning and knowledge can be lost or distorted during the filtering process, negatively influencing the communication experience.

The culture of an organization can significantly influence the information filtering process, as well as the overall perspective of knowledge within an organization. For instance, the culture of a conservative organization may innately suppress or reject knowledge that might lead to change. It is a human tendency to want to preserve the status quo (Wasdell, 2011). An organization that wants to successfully embrace change must first evaluate how 
its organizational culture portrays knowledge so that it can ensure a positive communication experience throughout the organization. A negative communication experience can undermine a change initiative, even to the point of absolute failure.

An organization that does not acknowledge the value of knowledge and actively pursue knowledge management will not be able to operate successfully in today's Information Age. Because knowledge management poses many challenges, it may be difficult for organizations to include it in strategic management; however, today's environment requires its inclusion.

\section{Background and Literature Review}

Today's organizations are operating in an environment where knowledge is power. As organizations vie for a competitive advantage, knowledge management has become a key element worthy of significant consideration (Cantner, Joel, \& Schmidt, 2009; C. W. Chong, Chong, \& Gan, 2011; Guidice, Heames, \& Wang, 2009). While the importance of knowledge management on organizational success is becoming more widely accepted, there has yet been no empirical research that specifically addresses the influence of organizational structure type, or management level, on knowledge management practices in organizations. The potential to increase competitive advantage based on an understanding of this influential relationship is substantial. Conversely, a failure to recognize this relationship has the potential to significantly limit organizational performance and ultimate success.

Organizational strategy is an ever-changing, ever-evolving element of organizational survival and success. It determines long-term goals, establishes the appropriate course of action, and drives the distribution of resources (Kipley \& Lewis, 2011). The relationship of structure and strategy has received substantial attention in literature, as has the significance of knowledge within an organization. However, the notion of an organization's structure influencing knowledge management practices within the organization has not been specifically evaluated in existing literature. Additionally, the concept of management level as an influence on knowledge management practices has not been evaluated in current literature. The models within this study provide a framework with which to evaluate these relationships.

Organizational structure and knowledge management effectiveness are two key concepts at the core of this study. Henry Mintzberg's seminal work on organizational configurations (1983) provided an early basis for understanding organizational structures. Today, basic constructs of knowledge management are understood as a combination of established theories and research from additional authors as Chuong (2011; 2006), Hari (2005), and Costanzo (2008), and many others.

\subsection{Organizational Structure}

Literature identifies five established organizational structure types, which have been adapted to fit this study. Mintzberg's original structure types are the Simple Structure, Machine Bureaucracy, Professional Bureaucracy, Divisional Form, and Adhocracy (Mintzberg, 1983). In this study, the organizational types have been identified more simply as adhocracy, strategic business unit (SBU), divisional, functional, and matrix. The adaptation of Mintzberg's classifications is a result of changing times. Since the time when Mintzberg defined these classifications in 1983, industry has adjusted to shifting environments. The framework of the original classifications is very much still relevant, though the names of the classification have been adapted to better represent today's times.

\subsubsection{Adhocracy}

The adhocratic organizational structure is one that adapts readily and promptly to meet organizational needs. This kind of organization is typically young and small, and may not yet possess sophisticated technological resources (Mintzberg, 1983). This type of organization can be thought of as "organic", meaning the organization does not operate under rigid formalities, but rather on the relationships and flexibility of those individuals within the organization (Burns \& Stalker, 1994).

While the organization may be young and relatively simple, it can still be dynamic, especially in its top management. Whether comprising one individual or a small group, top management may be vibrant, strong-willed, and possibly even aggressive. Informal structural configurations enable an adhocracy to be flexible and make decisions quickly, which is attractive in dynamic and turbulent environments. Such organizations exhibit a strong sense of adaptability and sense of mission as well (Mintzberg, 1983). 


\subsubsection{SBU Structure}

Formalization is important in an SBU structure. Analysts document every aspect of the work processes and then produce formalized procedures that are required in operating processes (Martínez-León \& Martínez-García, 2011). Strategy is a top-down function with heavy emphasis on action planning (Mintzberg, 1983). Decisionmaking, strategy planning, and work processes are managed at the top, leaving little room, if any, for individual discretion in the workplace.

The simple and stable work that is a result of this structure type minimizes administrative needs, which is a benefit of the SBU structure. Additionally, it is the only structure that is "supportive of the need for precise, simple, and routine activities" (Mintzberg, 1983, p. 176). However, it is this very nature of work that presents a number of challenges. The repetitiveness of work increases the potential for human error. Additionally, this model presents a constant conflict between engineering efficiency and employee job satisfaction. The organization is essentially obsessed with control, and it can only be successful in a stable environment where change is infrequent and predictable.

In addition to operating most successfully in simple, stable environments, SBU structures are geared toward mass-production-type organizations. Often these organizations are old and large. It is also most common to see this type of organizational structure in highly regulating organizations that operate with low dependency on technology or technical systems.

\subsubsection{Divisional Structure}

The SBU structure type is quite similar to the divisional structure type. This study uses the term "divisional" as employed by Mintzberg in his previous studies.

Divisional structure types emphasize divisionalization over decentralization. Control within the organization is essentially determined within the separate divisions of the organization. Duplication of operational functions is a strategic decision that is made so as to minimize the interdependence between divisions.

An obvious benefit of the divisional organizational structure type is risk diversification, also known as "strategic invulnerability" in the works of Igor Ansoff (Ansoff, 1984). Clearly, with an operating structure that promotes independence for each of the divisions, risk at the global level is significantly reduced. Strategically, this shields the organization as a whole from the unique risks that individual divisions may face, making the firm essentially strategically invulnerable. Additionally, divisional structures enable the efficient allocation of capital, increases strategic responsiveness, and provide for promotional opportunities for employment growth and satisfaction (Mintzberg, 1983).

A primary challenge present with this kind of organizational structure is the potential of fragmentation of knowledge management practices. Knowledge sharing is contained within divisions, information is filtered based on divisional needs, and the transfer of knowledge throughout the organization is disjointed at best.

Most often this organizational structure type is adopted by organizations within the private sector, including many organizations listed in the Fortune 500 (Mintzberg, 1983). The structure is optimal for market diversity and/or organizations that operate in multiple locations or on multiple campuses. Most organizations of this type have been around for a while and are large in size.

\subsubsection{Functional Structure}

Within a functional structure, the emphasis is on the professional skills of the employees. The extensive autonomy granted in a functional structure is both a benefit and a challenge. Autonomy can enable individuals to think freely and take risks, but it can also lead to the misuse of discretion. Individuals can succumb to professional blinders that propel them along a particular path with no regard to checks and balances (Mintzberg, 1983). Additionally, the functional structure can engender a political environment that may spur internal conflicts among individuals. Further challenges include the tendency to pigeonhole individuals based on their skill set and specialization. This can also lead to inflexibility, concerning both the individual and the organization.

The democratic nature of the functional structure makes the structure type attractive to complex, yet stable environments, where expert power is valued over legitimate power (as opposed to the value of the SBU structure). Representative organizations may include universities, hospitals, school systems, and public accounting firms, among others (Mintzberg, 1983). 


\subsubsection{Matrix Structure}

The matrix can be considered a blend of functional and divisional structure characteristics. Similar to the "organic" nature of the adhocracy addressed earlier, the matrix structure enables an organization to be responsive in dynamic and complex environments. Additionally, the emphasis placed on learning and risk-taking allows for the potential of sophisticated innovation. The true benefit of a matrix structure is in its ability to create and manage knowledge effectively.

The matrix structure possesses its own unique set of challenges. For example, the element of freedom identified as a benefit earlier also presents the potential for ambiguity, inefficiencies, and misinterpretations (Mintzberg, 1983). Also challenging is the lack of standardization among the skills of the professionals with regard to coordination efforts. Both the functional structure and the matrix structure place high value on professional skills, but whereas the functional structure emphasizes standardization of skills, the matrix structure does not. The lack of standardization can cause added organizational challenges. As explained by Ashkenas, "The matrix is ingenious in theory but confusing in practice" (Ashkenas, Ulrich, Jick, \& Kerr, 2002, p. 120). He also introduces the term "organizational schizophrenia" when discussing the challenges posed by the loose operational structure or standardization within a matrix organization.

Organizations best suited for a matrix structure are those which require a combination of professional and operational skill sets and inter-organizational coordination efforts that will enable the organization to optimally deliver products or services to meet client needs. These organizations will likely devise and use liaison mechanisms that assist and enhance the cross-functional efforts of the various resources through the organization. Organizations that operate within a matrix structure may include those within dynamic and fast-paced industries, such as the field of technology.

\subsection{Management Level}

Though managerial hierarchies take different forms according to the different organizational structure types, as noted above, levels of management exist in all organizations. There consistently exists, at minimum, levels such as non-managerial, mid-management, and executive or C-level.

\subsubsection{C-level}

C-level employees focus much of their time and attention on strategic tasks. It is a primary responsibility of executive level employees to ensure that the organization's mission is being achieved and that stakeholder needs are being addressed (Mintzberg, 1983). This level is often focused on the high-level perspective of strategic initiatives, and is less concerned with the details of the operations. Information flows both to and from executives, and decision-making is often conducted at this level. Additionally, social intelligence and relationship management play a crucial role in the upper levels of management (Akgün, Byrne, \& Keskin, 2007; Yeo, 2007).

\subsubsection{Mid-Management}

At the mid-management level, the middle line is a conduit for communication, information-filtering, and decision-making between the operating core and the strategic apex. Mid-management employees execute a critical function by acting as a bridge for the other levels (Rusaw, 2000). What information is passed up and/or down is at the discretion of individuals who fill a mid-management position. These individuals balance strategic focus with daily operations (Van Marrewijk, 2010), and it behooves them to master the art of message delivery. Tailoring messages specifically to the intended audience is a skill that significantly influences the impact of the message (Johansson \& Heide, 2008).

\subsubsection{Non-Managerial}

The third level of management addressed in this study is the non-managerial level. This level is comprised of the largest number of employees. These individuals are primarily focused on executing the daily operations of the organization according to implementation strategies determined by upper levels of management (Jacobides, 2007; Mintzberg, 1983). They are provided with direction "from above", and may or may not be consulted with for feedback and first-hand knowledge that will then be escalated back up through the ranks of the organization.

Responsibilities differ among management levels, and accordingly, perceptions differ as well. Individuals are tasked with different areas of focus, and naturally, will develop individual perceptions. However, literature identifies that both superiors and subordinates feel they initiate more interactions with the other than they receive, and that the adequacy and quality of interactions they initiate are higher than what they receive (Hatfield \& Huseman, 1982). While differences in perception are natural and expected, the perpetual absence of 
congruence may be evidence of communication problems that can negatively impact organizational outcomes (Hatfield \& Huseman, 1982).

\subsection{Knowledge Management}

Regardless of the size, type, or structure of an organization, knowledge is a known critical asset that is a requirement for survival (S. C. Chong et al., 2011). When the structure of an organization is best suited for its organizational needs, then the organization will operate most effectively (Doty, Glick, \& Huber, 1993). Part of this effectiveness is derived from knowledge management practices that emerge from the organizational structure. The knowledge management practices identified in this study are knowledge transfer, information filtering, knowledge-sharing training, and knowledge culture.

\subsubsection{Knowledge Transfer}

Knowledge transfer can be defined as the movement of knowledge between its origin and destination (Bosua \& Scheepers, 2007). Some further define the concept as a diffusion of knowledge within a social system (Rosenblatt, 2011). As this study aims to integrate practical applications, Bose's managerial interpretation of knowledge transfer is of particular interest. According to Bose, the purpose of knowledge transfer is to get the right information to the right people at the right time so they can make organizational decisions based on this information (Bose, 2009). Ultimately, the objective of knowledge transfer is to "promote and facilitate knowledge sharing, collaboration, and networking for better decision-making and effective problem solving" (S. C. Chong et al., 2011, p. 503).

While the ownership of knowledge exists at both the individual level and the group/organizational level, it is the integration of this knowledge at the collective levels that creates efficiencies and advantages for an organization (Herschel \& Jones, 2005). Managers often serve to help facilitate this integration process. In fact, managers often become "knowledge brokers" within an organization whereby they act as a kind of "bridge" that allows for knowledge transfer and integration (Costanzo \& Tzoumpa, 2008).

\subsubsection{Information Filtering}

Information filtering addresses the question of which information to provide to whom, when, and in which form (Christensen, 2002). It is an important strategic issue within organizations and the concept is generally understood to involve technology (Costanzo \& Tzoumpa, 2008). Technology certainly has its place in information filtering (S. C. Chong et al., 2011), yet readers are cautioned against succumbing to the illusion that technology is an end-all solution for complex problems (Smoliar, 2003). When human beings are involved, a technology solution alone is insufficient for complex problem solving. For the purposes of this study, information filtering will refer to the human rather than to the technological process.

Lines of communication may be formal or informal. The formal lines of communication generally address the upward, downward, and horizontal movement of messages (Brownell, 1991). Informal lines of communication may involve some of these considerations, but may also include any fathomable angle of message movement as well. Generally, in a traditional hierarchy, information filters up the organization to those in power (Ashkenas et al., 2002). Within other settings, the horizontal and vertical lines of communication intersect at the middle management level, thereby placing on middle managers the responsibility to further direct information in whichever direction is necessary (Costanzo \& Tzoumpa, 2008). Once again, the manager acts as a "bridge" for the movement of information.

Effective information filtering is not a simple matter of aligning the right resources. There are many social challenges to information filtering, including one-sided communication flows, suppression of information, information overload, and inaccurate message interpretation (Kitchen \& Daly, 2002). Also challenging is the codification of tacit knowledge, getting the information into a distributable format (Ting, Wang, Tse, \& Ip, 2011). Widespread information distribution is an essential component of knowledge management.

\subsubsection{Knowledge-Sharing Training}

Information is only beneficial to an organization if the members of the organization know how to access and use that information. Knowing how to seek and retrieve information is an essential aspect of behavior during times of problem-solving and decision-making (Wu, 2011).

Efficiency of knowledge sharing increases efficiency in work productivity. Yet a significant challenge within organizations is that up to 80 percent of business information is not quantitative or structured in a way that can be captured in a database (Herschel \& Jones, 2005). As such, it may be no surprise that an individual can spend in excess of 40 percent of his/her time in a typical work day processing work-related information (Zhuang, Qiu, 
\& Peng, 2011). Processing mediums may include emails, instant messages, phone calls, and conference calls. The knowledge-sharing training initiatives in place within an organization can help to streamline the knowledge management process (Bosua \& Scheepers, 2007; Kumar \& Ganesh, 2011; Levy, 2011).

\subsubsection{Knowledge Culture}

Culture significantly impacts how individuals within the organization communicate. How people receive, store, and interpret information is influenced by the interpretive schema, routines, procedures, and norms of the organization (Akgün et al., 2007). It can be argued that communication is a social process of interaction and/or interpretation in an effort to make sense and meaning of organizational actions and events (Mazzei, 2010). Smoliar (2003) refers to this socialization concept as "the sociology of knowledge" whereby knowledge is the product of these interactions and interpretations.

An effective and successful knowledge culture absolutely requires the visible support of top leadership (Bose, 2009; Cantner et al., 2009; Cheung, Li, Shek, Lee, \& Tsang, 2007; S. C. Chong et al., 2011; Herschel \& Jones, 2005). This is a condition of success. The organization must nurture an environment that promotes open knowledge sharing, collaboration, and learning. Top management must lead the effort, not just through verbal support, but by becoming change agents within the organization (Herschel \& Jones, 2005).

\section{Research Design and Methodology}

\subsection{Research Questions and Hypotheses}

It was the intention of this study to evaluate the following eight research questions by testing the following eight hypotheses:

RQ1: What is the difference between organizational structure types in terms of perceived level of knowledge transfer?

H1: There is a significant difference between organizational structure types in terms of perceived level of knowledge transfer.

Based on the characteristics of a matrix organizational structure type, it was expected that the results of the study would identify the matrix organizational structure type as exhibiting the highest perceived level of knowledge transfer, relative to the other organizational structure types.

RQ2: What is the difference between organizational structure types in terms of perceived level of information filtering?

$\mathrm{H} 2$ : There is a significant difference between organizational structure types in terms of perceived level of information filtering.

Based on the characteristics of an adhocracy organizational structure type, it was expected that the results of the study would identify the adhocracy organizational structure type as exhibiting the highest perceived level of information filtering, relative to the other organizational structure types.

RQ3: What is the difference between organizational structure types in terms of perceived level of knowledge-sharing training?

H3: There is a significant difference between organizational structure types in terms of perceived level of knowledge-sharing training.

Based on the characteristics of a SBU organizational structure type, it was expected that the results of the study would identify the SBU organizational structure type as exhibiting the highest perceived level of knowledge-sharing training, relative to the other organizational structure types.

RQ4: What is the difference between organizational structure types in terms of perceived level of knowledge culture?

H4: There is a significant difference between organizational structure types in terms of perceived level of knowledge culture.

Based on the characteristics of a matrix organizational structure type, it was expected that the results of the study would identify the matrix organizational structure type as exhibiting the highest perceived level of knowledge culture, relative to the other organizational structure types.

RQ5: What is the difference between management levels in terms of perceived level of knowledge transfer?

H5: There is a significant difference between management levels in terms of perceived level of knowledge transfer. 
Based on the characteristics of the non-managerial management level, it was expected that the results of the study would identify the non-managerial management level as exhibiting the highest perceived level of knowledge transfer, relative to the other management levels.

RQ6: What is the difference between management levels in terms of perceived level of information filtering?

H6: There is a significant difference between management levels in terms of perceived level of information filtering.

Based on the characteristics of the mid-management management level, it was expected that the results of the study would identify the mid-management level as exhibiting the highest perceived level of information filtering, relative to the other management levels.

RQ7: What is the difference between management levels in terms of perceived level of knowledge-sharing training?

H7: There is a significant difference between management levels in terms of perceived level of knowledge-sharing training.

Based on the characteristics of the C-level/executive management level, it was expected that the results of the study would identify the C-level/executive level as exhibiting the highest perceived level of knowledge-sharing training, relative to the other management levels.

RQ8: What is the difference between management levels in terms of perceived level of knowledge culture?

H8: There is a significant difference between management levels in terms of perceived level of knowledge culture.

Based on the characteristics of the C-level/executive management level, it was expected that the results of the study would identify the C-level/executive level as exhibiting the highest perceived level of knowledge culture, relative to the other management levels.

The corresponding null hypotheses were considered in the research methodology. The null hypotheses stated that there was no difference between the respective variables.

\subsection{Research Model}

The research model is the focus of this research study. Figure 1 shows a visual representation of the research model, which specifically identifies organizational structure types and management levels, and their influences on four constructs of knowledge management, including knowledge transfer, information filtering, knowledge sharing, and knowledge culture.

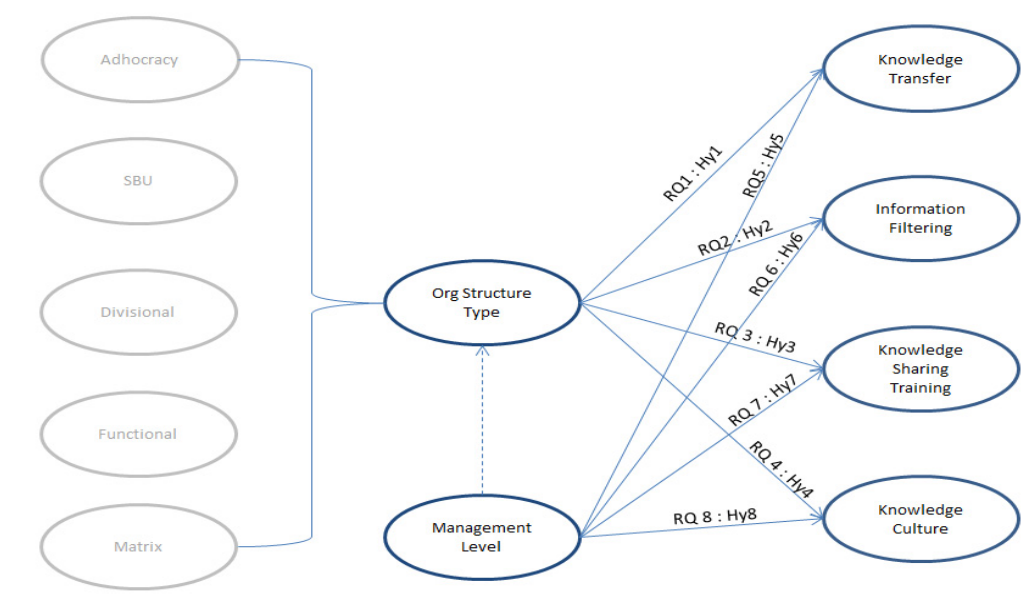

Figure 1. Research Model

Each of the five organizational structure types has its own impact on the knowledge management practices within an organization. Management levels also have the opportunity to influence the knowledge management practices within an organization. 


\subsection{Research Variables}

The variables used in this research study were conceived through practical experience and review of existing literature. Specifically, several published dissertation referenced during the process of defining these variables include authors Wei Zheng, David Bray, Trevor Smith, and Tricia Behnke (Behnke, 2010; Bray, 2008; Smith, 2006; Zheng, 2005).

Table 1 provides a summary overview of the independent variables (IV) and dependent variables (DV) used in this research study. A conceptual definition and operational definition are provided for each variable.

Table 1. Research variables with conceptual and operational definitions

\begin{tabular}{|c|c|c|}
\hline Variable & Conceptual Definition & Operational Definition \\
\hline $\begin{array}{l}\text { Organizational } \\
\text { Structure Type (IV) }\end{array}$ & $\begin{array}{l}\text { The formal framework of an organization, including such concepts } \\
\text { as organizational hierarchy, processes and procedures, and } \\
\text { formalization }\end{array}$ & $\begin{array}{l}\text { One single-response question that } \\
\text { identifies the organization as one of the } \\
\text { five structure types identified in this study }\end{array}$ \\
\hline $\begin{array}{l}\text { Management Level } \\
\text { (IV) }\end{array}$ & $\begin{array}{l}\text { The relative position held by an individual with regard to the } \\
\text { organizational hierarchy of an organization }\end{array}$ & $\begin{array}{l}\text { One single-response question that } \\
\text { identifies the management level as one of } \\
\text { the three management levels identified in } \\
\text { this study }\end{array}$ \\
\hline $\begin{array}{l}\text { Knowledge Transfer } \\
\text { (DV) }\end{array}$ & $\begin{array}{l}\text { The process through which one unit of the organization is affected } \\
\text { by the experience of another }\end{array}$ & $\begin{array}{l}\text { 7-pt scale measuring } 1 \text {-strongly disagree, } \\
\text { 7-strongly agree }\end{array}$ \\
\hline $\begin{array}{l}\text { Information Filtering } \\
\text { (DV) }\end{array}$ & $\begin{array}{l}\text { The process of distributing specific information to specific units } \\
\text { within an organization for specific purposes }\end{array}$ & $\begin{array}{l}\text { 7-pt scale measuring } 1 \text {-strongly disagree, } \\
\text { 7-strongly agree }\end{array}$ \\
\hline $\begin{array}{l}\text { Knowledge-Sharing } \\
\text { Training (DV) }\end{array}$ & $\begin{array}{l}\text { The pursuit of initiatives undertaken by an organization to train } \\
\text { individuals within the organization about the process available for } \\
\text { sharing knowledge within and among the various organizational } \\
\text { components }\end{array}$ & $\begin{array}{l}\text { 7-pt scale measuring } 1 \text {-strongly disagree, } \\
\text { 7-strongly agree }\end{array}$ \\
\hline $\begin{array}{l}\text { Knowledge Culture } \\
\text { (DV) }\end{array}$ & $\begin{array}{l}\text { The undertones of organizational norms and values that specifically } \\
\text { address the significance of knowledge management practices within } \\
\text { an organization for both individuals and the organization as a whole }\end{array}$ & $\begin{array}{l}\text { 7-pt scale measuring } 1 \text {-strongly disagree, } \\
\text { 7-strongly agree }\end{array}$ \\
\hline
\end{tabular}

\subsection{Research Strategy}

The statistical test used on each hypothesis was ANOVA. Descriptive statistics were used to compute means, variances, and standard deviations. The data were statistically analyzed in SPSS for each of the research hypotheses. A value of $5 \%$ was used as the threshold for assessment of statistical significance $(p<.05)$.

\subsection{Data Collection}

The data used in this study werecollected from an online research survey completed by participants who are employed within the geographical location of San Diego County. Research participants were reached via Snowball sampling: participants were targeted initially by way of direct email, and subsequent participants were reached by direct communication from the initial participants.

In total, 155 individuals from San Diego County complete the survey. Responses were obtained from a variety of industries, and included for-profit and not-for-profit organizations. Each of the five organizational structure types and each of the three management levels were adequately represented in the study.

\subsection{Instrument}

The survey instrument was managed via KwikSurveys.com, an online survey site. The survey was created within the site, distributed with a direct link to the site, and the raw data werecollected directly from the site.

The majority of the questions on the instrument were borrowed directly from previously published dissertations. An initial pilot test was conducted on the survey, and suggestions for improvements were taken into consideration. The survey was also provided to the dissertation committee members for review prior to distribution. 
The initial page presented to survey participants once the survey link was initiated provided a summary that included background information about the researcher and the study, procedures for the online survey, risks and benefits to the participants, confirmation of confidentiality, and contact information should participants have comments or questions. The participant's bill of rights was thoroughly explained, as required by the Alliant International University Institutional Review Board. Participants were then able to click "Next" or "Cancel." By clicking "Next," participants indicated that they had read the consent form and agreed to participate in the study.

The data elements for the survey were selected directly from previously published dissertations and literary works. The survey was also presented to a pilot group for testing and feedback, and was presented to the dissertation committee for review. The goal of these reviews was to ensure content validity and clarity of the questions.

All variables were calculated from responses to multiple questions. Reliability of the variables used in the research was tested using Cronbach's alpha. The results of the Cronbach's alpha indicated good reliability of test items above 0.7. Table 2 identifies the results of the Cronbach's alpha.

Table 2. The results of the Cronbach's alpha

\begin{tabular}{lll}
\hline Variable & Survey Question & $\begin{array}{l}\text { Cronbach's } \\
\text { Coefficient }\end{array}$ \\
\hline Knowledge Transfer & $11,12,13,14,15,16,17,18$ & .883 \\
Information Filtering & $19,20,21,22,23,24,25,26,27$ & .922 \\
Knowledge-Sharing Training & $28,29,30,31,32,33,34$ & .882 \\
Knowledge Culture & $35,36,37,38,39,40,41,42,43$ & .800 \\
\hline
\end{tabular}

\subsection{Data Analysis}

Responses to the questions on the survey were coded into an Excel spreadsheet for calculation and statistical analyses. All questions were structured to be answered on a 7-point numerical scale. Variables were determined as the arithmetic mean of multiple elements. Only survey responses that provided answers to all survey questions were used in this study.

All hypotheses were tested using ANOVA. The criterion for accepting or rejecting a hypothesis was a statistical significance level of less than $5 \%(p<.05)$. This significance represents the probability of rejecting a null hypothesis that is true.

\subsection{Data Screening}

The survey instrument was designed in such a way that participants could only proceed through the survey if answers were provided to all questions. Only completed surveys were used in the study, so the concern of missing responses was a non-issue in this research study.

\section{Results and Conclusions}

\subsection{Results}

A summary of the research findings is presented below and in Table 3. Three of the eight hypotheses were supported at significance levels less than $3 \%(p<.03)$.

Table 3. Summary of null hypotheses testing

\begin{tabular}{|c|c|c|c|}
\hline Null Hypothesis & Test & $p$ & Results of Findings \\
\hline $\begin{array}{l}\mathrm{H} 1_{0} \text { - No difference between organizational structure types in terms of } \\
\text { perceived levels of knowledge transfer }\end{array}$ & ANOVA & .022 & Failed to reject \\
\hline $\begin{array}{l}\mathrm{H} 2_{0} \text { - No difference between organizational structure types in terms of } \\
\text { perceived levels of information filtering }\end{array}$ & ANOVA & .003 & Failed to reject \\
\hline $\begin{array}{l}\mathrm{H} 3_{0}-\text { No difference between organizational structure types in terms of } \\
\text { perceived levels of knowledge- sharing training }\end{array}$ & ANOVA & .298 & Rejected \\
\hline $\begin{array}{l}\mathrm{H}_{0} \text { - No difference between organizational structure types in terms of } \\
\text { perceived levels of knowledge culture }\end{array}$ & ANOVA & .000 & Failed to reject \\
\hline $\begin{array}{l}\mathrm{H} 5_{0}-\text { No difference between management levels in terms of perceived levels of } \\
\text { knowledge transfer }\end{array}$ & ANOVA & .820 & Rejected \\
\hline
\end{tabular}




\begin{tabular}{|c|c|c|c|}
\hline $\begin{array}{l}\mathrm{H}_{0}-\text { No difference between management levels in terms of perceived levels of } \\
\text { information filtering }\end{array}$ & ANOVA & .938 & Rejected \\
\hline $\begin{array}{l}\mathrm{H} 7_{0}-\text { No difference between management levels in terms of perceived levels of } \\
\text { knowledge-sharing training }\end{array}$ & ANOVA & .470 & Rejected \\
\hline $\mathrm{H} 8_{0}-$ No difference between management levels in terms of perceived levels of & ANOVA & .988 & Rejected \\
\hline
\end{tabular}

knowledge-sharing training

Hypothesis 1 was supported at a significance level below 3\% $(p<.03)$. Hypotheses 2 and 4 were also supported a statistical significance level well below $1 \%(p<.01)$. The results for hypotheses 1,2 , and 4 indicate that there is significant difference between organizational structure types in terms of perceived levels of knowledge transfer, information filtering and knowledge culture, respectively. The results of these hypotheses are displayed in in tables 4,5 , and 6 .

Table 4. Findings of hypothesis 1

\begin{tabular}{llllll}
\hline & Sum of Squares & df & Mean Square & F & Sig. \\
\hline Between Groups & 18.164 & 4 & 4.541 & 2.960 & .022 \\
Within Groups & 230.132 & 150 & 1.534 & & \\
Total & 248.297 & 154 & & \\
\hline
\end{tabular}

Table 5. Findings of hypothesis 2

\begin{tabular}{llllll}
\hline & Sum of Squares & df & Mean Square & F & Sig. \\
\hline Between Groups & 23.293 & 4 & 5.823 & 4.306 & .003 \\
Within Groups & 202.861 & 150 & 1.352 & & \\
Total & 226.155 & 154 & & & \\
\hline
\end{tabular}

Table 6. Findings of hypothesis

\begin{tabular}{llllll}
\hline & Sum of Squares & df & Mean Square & F & Sig. \\
\hline Between Groups & 11.136 & 4 & 2.784 & 5.489 & .000 \\
Within Groups & 76.080 & 150 & .507 & & \\
Total & 87.216 & 154 & & & \\
\hline
\end{tabular}

The results of hypotheses 1, 2, and 4 indicate that the knowledge management practices of knowledge transfer, information filtering, and knowledge culture are influenced by organizational structure type. The results of hypotheses 1, 2, and 4 can be interpreted as suggesting that the characteristics of organizational structure types should be taken into consideration while developing initiatives with regard to knowledge management practices.

Two of the three supported hypotheses produced results that aligned with the expected results. The results of hypothesis 1 and hypothesis 4 identified the matrix organizational structure type as exhibiting the highest perceived level of knowledge transfer and knowledge culture, relative to the other organizational structure types, as was expected. Characteristics of a matrix organizational structure, such as its blend of commitment to the functional and divisional requirements of an organization, contribute to its ability to effectively transfer knowledge within and among individuals in the organization, and to exhibit a dedication to upholding knowledge as a cornerstone of the organization's culture.

The expectation of hypothesis 2 was that the adhocracy organizational structure type would exhibit the highest perceived level of information filtering, relative to the other organizational structure types. This expectation was due in large part to the flat nature of the organizational hierarchy. However, the results of the survey identified the matrix as exhibiting the highest perceived level of information filtering, relative to the other organizational structure types. The "organic" nature of an adhocracy, combined with its tendency toward the transfer of knowledge, likely contributed to these survey results.

Hypothesis 3 was not supported. It was expected that the results of the survey would identify the SBU organizational structure type as exhibiting the highest perceived level of knowledge-sharing training, relative to the other organizational structure types, due to the SBU's driving force of formalization.However, the results 
from hypothesis 3 suggest that perceived levels of knowledge-sharing training do not differ significantly between organizational structure types. The results of hypothesis 3 are displayed in table 7 .

Table 7. Findings of hypothesis 3

\begin{tabular}{llllll}
\hline & Sum of Squares & df & Mean Square & F & Sig. \\
\hline Between Groups & 7.056 & 4 & 1.764 & 1.236 & .298 \\
Within Groups & 214.131 & 150 & 1.428 & & \\
Total & 221.187 & 154 & & & \\
\hline
\end{tabular}

The failure to reject the null hypothesis for hypothesis 3 indicates there is no valued added through efforts to design knowledge-sharing training initiatives in accordance with known characteristics of organizational structure types.

Hypotheses 5-8 were not supported. The aforementioned expected results were not supported with the results of the survey. The results for hypotheses 5, 6, and 8, in particular, show virtually no difference between management levels in terms of perceived levels of knowledge transfer, information filtering, knowledge-sharing training, and knowledge culture, respectively. The results of these hypotheses are displayed in in tables $8,9,10$, and 11 .

Table 8. Findings of hypothesis 5

\begin{tabular}{llllll}
\hline & Sum of Squares & df & Mean Square & F & Sig. \\
\hline Between Groups & .655 & 2 & .328 & .199 & .820 \\
Within Groups & 245.549 & 149 & 1.648 & & \\
Total & 246.204 & 151 & & & \\
\hline
\end{tabular}

Table 9. Findings of hypothesis 6

\begin{tabular}{llllll}
\hline & Sum of Squares & df & Mean Square & F & Sig. \\
\hline Between Groups & .189 & 2 & .094 & .064 & .938 \\
Within Groups & 218.647 & 149 & 1.467 & & \\
Total & 218.836 & 151 & & & \\
\hline
\end{tabular}

Table 10. Findings of hypothesis 7

\begin{tabular}{llllll}
\hline & Sum of Squares & df & Mean Square & F & Sig. \\
\hline Between Groups & 2.199 & 2 & 1.100 & .760 & .470 \\
Within Groups & 215.741 & 149 & 1.448 & & \\
Total & 217.941 & 151 & & & \\
\hline
\end{tabular}

Table 11. Findings of hypothesis 8

\begin{tabular}{llllll}
\hline & Sum of Squares & df & Mean Square & F & Sig. \\
\hline Between Groups & .014 & 2 & .007 & .012 & .988 \\
Within Groups & 86.524 & 149 & .581 & & \\
Total & 86.538 & 151 & & & \\
\hline
\end{tabular}

The failure to reject the null hypothesis for hypotheses 5, 6, 7, and 8 suggests there is no value added through efforts to design knowledge management strategies in accordance with known characteristics of different management levels.

\subsection{Conclusions}

The results from this study indicate that the knowledge management practices of knowledge transfer, information filtering, and knowledge culture are influenced by organizational structure type. Thus, it can be concluded that a need exists for management to analyze the structure of its organization to identify opportunities for maximizing efforts related to knowledge management practices. The matrix organizational structure type has 
been identified as exhibiting high perceived levels of knowledge management practices relative to other organizational structure types. The characteristics of this organizational structure types could be further reviewed by management to identify and optimize operations and practices within their own organizations.

According to the results of this study, the knowledge management practice of knowledge-sharing training is not influenced by organizational structure type. Additionally, the results from this study indicate no significant difference between management levels on the four sub-constructs of knowledge management practices. The failure to identify a significant difference for these hypotheses indicates an absence of impact of significance. From a practical perspective, there is no value added through efforts to design knowledge management strategies in accordance with known characteristics of organizational structure types or management levels.

\section{Assumptions, Limitations, and Future Work}

\subsection{Assumptions}

The following assumptions were made in developing, conducting, and analyzing this study's research model and data.

1) The research methods and procedures used in this study were appropriate for the intent of this study.

2) The respondents were willing and able to understand and answer the questions on the survey.

3) The respondents were willing and able to complete an online survey using a computer and the Internet.

4) The respondents gave honest answers to the best of their ability.

5) The respondents were able to evaluate organizational behaviors and relationships in an accurate and objective manner.

6) The respondents were representative of all recipients, including those who did not choose to respond.

7) The items used to measure organizational structure and knowledge management practices were extensive enough to adequately represent the complexity of these variables.

\subsection{Limitations}

Potential limitations may have influenced the results of this study. Specifically, the survey questions were presented with similar formatting styles, and may therefore have caused "answer trending." This would mean that answers to questions were influenced by the pattern of previous questions.

Additionally, length of employment was not evaluated within the context of this study. It is possible that answers provided by newly hired employees were not accurately representative of the behaviors of the organization.

The data collection method of Snowball sampling also presents a potential limitation to this study. By its nature, Snowball sampling may have influenced the scope of survey recipients.

This research study gathered data from San Diego County in order to control the scope of the study. It is acknowledged that differences exist between different parts of the country, and that outcomes from this study are particular to San Diego County. It was assumed that expanding the scope of the study to include regions beyond San Diego County would introduce confounding variables that could influence the results of the study.

\subsection{Recommendations for Future Research}

A recommendation for future research would be to expand the testing parameters to include other acceptable analysis techniques to evaluate differences between the variables of this study.

Additionally, this study evaluated organizations of all objectives. It is recommended for future research to specifically evaluate for-profit firms and/or non-profit firms. Similarly, this particular study was inclusive of all industries. Future research could be conducted within specific industries to determine if particular industry influences exist.

It is also recommended for future research to extend the research model to other geographical populations. This study focused solely on organizations located within San Diego County. Applying the research model to different geographical locations may determine if additional influences exist. It is recommended to conduct this study in different regions of the U.S. as well as in different countries throughout the world.

Future research may also evaluate on demographic criterion such as age, gender, ethnicity, and income level. 
The data gathered for this research study werecollected by way of Snowball sampling. As discussed previously, this data collection method may have influenced the scope of the survey recipients. Therefore, it is recommended that this research model be tested with data collected from alternative collection methods.

\section{References}

Akgün, A. E., Byrne, J., \& Keskin, H. (2007). Organizational intelligence: a structuration view. Journal of Organizational Change Management, 20(3), 272-289. http://doi.dx.org/10.1108/09534810710740137

Ansoff, I. H. (1984). Implementing Strategic Management. Englewood Cliffs, NJ: Prentice-Hall International.

Ashkenas, R., Ulrich, D., Jick, T., \& Kerr, S. (2002). The Boundaryless Organization. San Francisco: Jossey-Bass Publishers.

Behnke, T. M. (2010). Knowledge Sharing at Work: An Examination of Organizational Antecedents. St. Ambrose University.

Bose, R. (2009). Advanced analytics: opportunities and challenges. Industrial Management \& Data Systems, 109(2), 155-172. http://doi.dx.org/10.1108/02635570910930073

Bosua, R., \& Scheepers, R. (2007). Towards a model to explain knowledge sharing in complex organizational environments. Knowledge Management Research \& Practice, 5(2), 93-109. http://doi.dx.org/10.1057/palgrave.kmrp.8500131

Bray, D. A. (2008). Knowledge Ecosystems: Technology, Motivations, Processes, and Performance. Emory University.

Brownell, J. (1991). Middle Managers: Facing the Communication Challenge. Cornell Hotel and Restaurant Administration Quarterly, 31(4), 52-59. http://doi.dx.org/10.1177/001088049103100417

Burns, T., \& Stalker, G. M. (1994). The Management of Innovation (3rd ed.). Oxford: Oxford University Press.

Cantner, U., Joel, K., \& Schmidt, T. (2009). The use of knowledge management by German innovators. Journal of Knowledge Management, 13(4), 187-203. http://doi.dx.org/10.1108/13673270910971923

Cheung, C. F., Li, M. L., Shek, W. Y., Lee, W. B., \& Tsang, T. S. (2007). A systematic approach for knowledge auditing: a case study in transportation sector. Journal of Knowledge Management, 11(4), 140-158. http://doi.dx.org/10.1108/13673270710762774

Chong, C. W., Chong, S. C., \& Gan, G. C. (2011). Inter-organizational knowledge transfer needs among small and medium enterprises. Library Review, 60(1), 37-52. http://doi.dx.org/10.1108/00242531111100568

Chong, S. C., Salleh, K., Noh, S., Ahmad, S., \& Sharifuddin, S. S. O. (2011). KM implementation in a public sector accounting organization: an empirical investigation. Journal of Knowledge Management, 15(3), 497-512. http://doi.dx.org/10.1108/13673271111137457

Chong, S. C., Wong, K. Y., \& Binshan, L. (2006). Criteria for measuring KM performance outcomes in organisations. Industrial Management \& Data Systems, 106(7), 917-936. http://doi.dx.org/10.1108/02635570610688850

Christensen, L. T. (2002). Corporate communication: the challenge of transparency. Corporate Communications: An International Journal, 7(3), 162-168. http://doi.dx.org/10.1108/13563280210436772

Costanzo, L. A., \& Tzoumpa, V. (2008). Enhancing organisational learning in teams: has the middle manager got a role? Team Performance Management, 14(3/4), 146-164. http://doi.dx.org/10.1108/13527590810883424

Doty, D. H., Glick, W. H., \& Huber, G. P. (1993). Fit, Equifinality, and Organizational Effectiveness: a Test of Two Configurational Theories. Academy of Management Journal, 36(6), 1196-1250. http://doi.dx.org/10.2307/256810

Garcia, D. J. J., De Reyna, Z. R., \& Garcia, A. P. J. (2010). Evidence-based administration for decision making in the framework of knowledge strategic management. The Learning Organization, 17(4), 343-363. http://doi.dx.org/10.1108/09696471011043108

Guidice, R. M., Heames, J. T., \& Wang, S. (2009). The indirect relationship between organizational-level knowledge worker turnover and innovation: An integrated application of related literature. The Learning Organization, 16(2), 143-167. http://doi.dx.org/10.1108/09696470910939215 
Hari, S., Egbu, C., \& Kumar, B. (2005). A knowledge capture awareness tool: An empirical study on small and medium enterprises in the construction industry. Engineering, Construction and Architectural Management, 12(6), 533-567. http://doi.dx.org/10.1108/09699980510634128

Hatfield, J. D., \& Huseman, R. C. (1982). Perceptual Congruence of Communication Related to Satisfaction: Moderating Effects of Individual Characteristics. Management, 25(2), 349-358.

Herschel, R. T., \& Jones, N. E. (2005). Knowledge management and business intelligence: the importance of integration. Journal of Knowledge Management, 9(4), 45-55. http://doi.dx.org/10.1108/13673270510610323

Jacobides, M. G. (2007). The Inherent Limits of Organizational Structure and the Unfulfilled Role of Hierarchy: Lessons from a Near-War. Organization Science, 18(3), 455-477. http://doi.dx.org/10.1287/orsc.1070.0278

Johansson, C., \& Heide, M. (2008). Speaking of change: three communication approaches in studies of organizational change. Corporate Communications: An International Journal, 13(3), 288-305. http://doi.dx.org/10.1108/13563280810893661

Kipley, D., \& Lewis, A. (2011). Strategic Management Incorporating Ansoff (1st ed.). Boston, MA: Pearson Custom Publishing.

Kitchen, P. J., \& Daly, F. (2002). Internal communication during change management. Corporate Communications: An International Journal, 7(1), 46-53. http://doi.dx.org/10.1108/13563280210416035

Kumar, A., \& Ganesh, L. S. (2011). Inter-individual knowledge transfer and performance in product development. The Learning Organization, 18(3), 224-238. http://doi.dx.org/10.1108/09696471111123270

Lerro, A., \& Schiuma, G. (2009). Knowledge-based dynamics of regional development: the case of Basilicata region. Journal of Knowledge Management, 13(5), 287-300. http://doi.dx.org/10.1108/13673270910988114

Levy, M. (2011). Knowledge retention: minimizing organizational business loss. Journal of Knowledge Management, 15(4), 582-600. http://doi.dx.org/10.1108/13673271111151974

Martínez-León, I. M., \& Martínez-García, J. A. (2011). The influence of organizational structure on organizational learning. International Journal of Manpower, 32(5/6), 537-566. http://doi.dx.org/10.1108/01437721111158198

Mazzei, A. (2010). Promoting active communication behaviours through internal communication. Corporate Communications: An International Journal, 15(3), 221-234. http://doi.dx.org/10.1108/13563281011068096

Mintzberg, H. (1983). Structures in Five: Designing Effective Organizations. Englewood Cliffs, NJ: Prentice-Hall Inc.

Rosenblatt, V. (2011). The impact of institutional processes, social networks, and culture on diffusion of global work values in multinational organizations. Cross Cultural Management: An International Journal, 18(1), 105-121. http://doi.dx.org/10.1108/13527601111104322

Rusaw, A. C. (2000). Uncovering training resistance: A critical theory perspective. Journal of Organizational Change Management, 13(3), 249-263. http://doi.dx.org/10.1108/09534810010330896

Smith, T. A. (2006). Knowledge Management and Its Capabilities Linked to the Business Strategy for Organizational Effectiveness. Nova Southeastern University.

Smoliar, S. W. (2003). Interaction management: The next (and necessary) step beyond knowledge management. Business Process Management Journal, 9(3), 337-353. http://doi.dx.org/10.1108/14637150310477920

Ting, S. L., Wang, W. M., Tse, Y. K., \& Ip, W. H. (2011). Knowledge elicitation approach in enhancing tacit knowledge sharing.

Tsoukas, H. (1996). The firm as a distributed knowledge system: a constructionist approach. Strategic Management, 17, 11-25.

Van Marrewijk, M. (2010). Strategic Orientations: Multiple Ways for Implementing Sustainable Performance. Technology and Investment, 1, 85-96. http://doi.dx.org/10.4236/ti.2010.12010

Wasdell, D. (2011). The dynamics of climate change: a case study in organisational learning. The Learning Organization, 18(1), 10-20. http://doi.dx.org/10.1108/09696471111095966

$\mathrm{Wu}$, I. C. (2011). Toward supporting information-seeking and retrieval activities based on evolving topic-needs. Journal of Documentation, 67(3), 525-561. http://doi.dx.org/10.1108/00220411111124578 
Yeo, R. K. (2007). Change interventions to organizational learning: bravo to leaders as unifying agents. The Learning Organization, 14(6), 524-552. http://doi.dx.org/10.1108/09696470710825132

Zheng, W. (2005). The Impact of Organizational Culture, Structure, and Strategy on Knowledge Management Effectiveness and Organizational Effectiveness. The University of Minnesota.

Zhuang, L., Qiu, Y., \& Peng, L. (2011). Is it the more the merrier?: An exploratory study into the growing problem of information overload. Journal of Technology Management in China, 6(1), 69-83. http://doi.dx.org/10.1108/17468771111105668

\section{Copyrights}

Copyright for this article is retained by the author(s), with first publication rights granted to the journal.

This is an open-access article distributed under the terms and conditions of the Creative Commons Attribution license (http://creativecommons.org/licenses/by/3.0/). 